\title{
Tau oligomers impair memory and induce synaptic and mitochondrial dysfunction in wild-type mice
}

\author{
Cristian A Lasagna-Reeves, Diana L Castillo-Carranza, Urmi Sengupta, Audra L Clos, George R Jackson and \\ Rakez Kayed ${ }^{*}$
}

\begin{abstract}
Background: The correlation between neurofibrillary tangles of tau and disease progression in the brains of Alzheimer's disease (AD) patients remains an area of contention. Innovative data are emerging from biochemical, cell-based and transgenic mouse studies that suggest that tau oligomers, a pre-filament form of tau, may be the most toxic and pathologically significant tau aggregate.
\end{abstract}

Results: Here we report that oligomers of recombinant full-length human tau protein are neurotoxic in vivo after subcortical stereotaxic injection into mice. Tau oligomers impaired memory consolidation, whereas tau fibrils and monomers did not. Additionally, tau oligomers induced synaptic dysfunction by reducing the levels of synaptic vesicle-associated proteins synaptophysin and septin-11. Tau oligomers produced mitochondrial dysfunction by decreasing the levels of NADH-ubiquinone oxidoreductase (electron transport chain complex I), and activated caspase-9, which is related to the apoptotic mitochondrial pathway.

Conclusions: This study identifies tau oligomers as an acutely toxic tau species in vivo, and suggests that tau oligomers induce neurodegeneration by affecting mitochondrial and synaptic function, both of which are early hallmarks in AD and other tauopathies. These results open new avenues for neuroprotective intervention strategies of tauopathies by targeting tau oligomers.

\section{Introduction}

The major biological functions of the microtubule-associated protein tau, include: microtubule assembly, axonal transport, neurite outgrowth, and stability of microtubules [1]. Most of the biological functions of tau are modulated by site-specific phosphorylation [2]. Tau selfassembly, aggregation, and accumulation in neurofibrillary tangles (NFTs) are hallmarks of Alzheimer's disease (AD) and other neurodegenerative diseases [3,4]. Although the importance of tau in AD and other tauopathies is well-established [5-7], unanswered is whether NFTs are the primary neurotoxic factor. Most research has focused on NFTs because of the reported correlation between NFTs and disease progression in the brains of $\mathrm{AD}$ patients [8-10]. However, recent data suggest that

\footnotetext{
* Correspondence: rakayed@utmb.edu

George P. and Cynthia Woods Mitchell Center for Neurodegenerative

Diseases, Departments of Neurology, and Neuroscience and Cell Biology, The University of Texas Medical Branch, Galveston, TX 77555-1045, USA
}

soluble pre-filament forms of tau may be the most toxic and pathologically significant forms of tau aggregates $[11,12]$. Cell death and synaptic lesions occur independently of formation of NFTs in h-tau mice expressing non-mutant human tau $[13,14]$. Hippocampal synapse loss and microgliosis precede formation of NFTs in the P301S transgenic mouse model (P301S Tg) [15]. Moreover, tau oligomers were biochemically characterized in a conditional model (rTg4510) expressing the P301L htau mutant. Surprisingly, the best correlate of neuronal loss and behavioral deficits in these models was the accumulation of oligomeric tau, whereas there was no relation with NFTs $[16,17]$. In addition, stereologic studies of human AD show that neuronal loss actually precedes NFT formation $[18,19]$. Granular tau oligomers were detected and biochemically isolated at very early stages of the disease, when clinical symptoms of $\mathrm{AD}$ and NFTs are believed to be absent $[20,21]$, and tau-positive fine granules were found in postmortem tissue from the

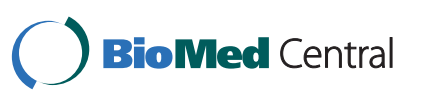

(c) 2011 Lasagna-Reeves et al; licensee BioMed Central Ltd. This is an Open Access article distributed under the terms of the Creative Commons Attribution License (http://creativecommons.org/licenses/by/2.0), which permits unrestricted use, distribution, and reproduction in any medium, provided the original work is properly cited. 
parkinsonism-dementia complex of Guam (PDC) tauopathy [22]. Even more recently, tau oligomers were detected in platelets from AD patients, suggesting that this species of tau protein could serve as a new biological marker for AD [23].

Mechanistic studies of aggregation of full-length tau protein in vitro revealed that tau aggregates by means of either a nucleation-dependent mechanism [24] or by the formation of intermediates [25]. In the present study, we investigated the neurotoxicity of different forms of tau in vivo by injecting well-characterized oligomers, fibrils, or monomers of full-length recombinant h-tau441 (2N4R) into the hippocampus of C57BL/6 wildmice. We found that the mice injected with tau oligomers presented with memory deficits in their novelobject recognition task, which is widely used for evaluating memory in AD mouse models [26-29].

We also determined the loss of synaptic-related proteins and mitochondrial respiratory chain components in conjunction with the activation of the mitochondrial dysfunction markers and the pro-apoptotic protein caspase-9. Our results strongly suggest that accumulation of tau oligomers result in learning impairment through the disruption of synaptic and mitochondrial functions.

\section{Methods}

\section{Preparation of tau oligomers and fibrils}

Recombinant tau protein (tau-441 (2N4R) M.Wt 45.9 $\mathrm{kDa})$ was expressed and purified as described [30,83]. In brief, we transformed the BL21 (DE3) strain of Escherichia coli with pET-28 plasmids and grown in LB medium at $37^{\circ} \mathrm{C}$ under vigorous shaking. At an $\mathrm{OD}_{600}$ of 0.4-0.6, we induced protein expression with $1 \mathrm{mM}$ isopropyl $\beta$-D-thiogalactoside. Bacteria were incubated for an additional $3 \mathrm{~h}$ and then centrifuged for $20 \mathrm{~min}$ at $3,500 \times g$. Pellets were resuspended in $500 \mathrm{mM} \mathrm{NaCl}$, $20 \mathrm{mM}$ PIPES (pH 6.5), $1 \mathrm{mM}$ EDTA, and $50 \mathrm{mM} 2-$ mercaptoethanol. After $10 \mathrm{~min}$ on ice, we sonicated the samples $3 \times 30 \mathrm{sec}$ at power setting seven. We pelleted the bacterial debris for $20 \mathrm{~min}$ at $10,000 \times g$ and soluble tau protein was precipitated from supernatant by using ammonium sulfate $(60 \%, \mathrm{~m} / \mathrm{V})$. After $1 \mathrm{~h}$ on ice, samples were centrifuged for $10 \mathrm{~min}$ at $10,000 \times g$. Pellets were resuspended in purified $\mathrm{H}_{2} \mathrm{O}, 2 \mathrm{mM}$ dithiothreitol (DTT), and loaded onto cation exchange column (Bio$\mathrm{Rad})$. Protein was eluted from the column in a 0.05-1 M $\mathrm{NaCl}$ gradient containing $20 \mathrm{mM}$ PIPES ( $\mathrm{pH}$ 6.5), 0.5 $\mathrm{mM}$ EDTA, and $2 \mathrm{mM}$ DTT. We analyzed the fractions using SDS-PAGE; and we pooled tau protein samples and added $5 \mathrm{mM}$ DTT. The protein was purified using Superdex column (Amersham Pharmacia). Elution occurred with $100 \mathrm{mM} \mathrm{NaCl}, 10 \mathrm{mM}$ PIPES (pH 6.5), 1 mM EDTA, and 2 mM DTT. Pooled samples of monomeric tau and added to $5 \mathrm{mM}$ DTT. At that point, the protein was $>95 \%$ pure, as assessed by SDS-PAGE. For storage, tau was precipitated overnight on ice with an equal volume of $\mathrm{MetOH}$, centrifuged for $20 \mathrm{~min}$ at $10,000 \times g$, washed once with $\mathrm{MetOH}$ and $2 \mathrm{mM}$ DTT, and stored at $-80^{\circ} \mathrm{C}$. Protein concentrations were determined at $276 \mathrm{~nm}$ in $6 \mathrm{M}$ guanidinium chloride. We treated the recombinant tau with $8 \mathrm{M}$ urea to obtain monomeric tau, then dialyzed overnight against $1 \times$ phosphate-buffered saline (PBS), $\mathrm{pH} 7.4$, normalized to $1 \mathrm{mg} / \mathrm{mL}$ with PBS and aliquots of tau monomer in PBS were kept at $-20^{\circ} \mathrm{C}$.

Tau oligomers were prepared as previously described [36]. Specifically, $300 \mu \mathrm{L}$ of the tau stock $(1 \mathrm{mg} / \mathrm{mL})$ was added to $700 \mu \mathrm{L}$ of PBS $1 \times$, final concentration $(0.3 \mathrm{mg} /$ $\mathrm{mL})$. Seven microliters of $\beta 42$ amyloid (A $\beta 42)$ oligomers $(0.3 \mathrm{mg} / \mathrm{mL})$ was added as seeds and the sample was mixed by pipetting for $1 \mathrm{~min}$. We incubated the sample at room temperature for $1 \mathrm{~h}$ on an orbital shaker. We purified the resulting tau oligomers by fast protein liquid chromatography (FPLC) and used them to seed a fresh sample of monomeric tau; after two rounds of seeding monomeric tau with purified tau oligomers, all A $\beta$ oligomer seeds are eliminated. The samples have no $A \beta$ as tested by either enzyme-linked immunosorbent assay (ELISA) or Western blotting using 4G8. This is not surprising since we used $(1: 140) \mathrm{A} \beta /$ tau ratio in the first round, which is less than the standard used in the literature as seeds to promote aggregation. After three rounds, there was less than 1:2,470,000 A $\beta /$ tau, which is below the detection limits of the methods available. To prepare the fibrils, tau oligomers were allowed to mix 1-2 days on the orbital shaker. Tau preparations were characterized by atomic force microscopy (AFM) by a non-contact tapping method (ScanAsyst-air) using a Multimode 8 AFM machine (Veeco, CA), and purified by size-exclusion chromatography, using an LC-6AD Shimadsu high-performance liquid chromatography (HPLC) system fitted with a TSK-GEL G3000 SWXL $(30 \mathrm{~cm} \times 7.8 \mathrm{~mm})$ column, Supelco-808541. PBS, pH 7.4, was used as the mobile phase, flow rate $0.5 \mathrm{~mL} / \mathrm{min}$. Gel filtration standard (Bio-Rad 51-1901) was used for calibrations.

\section{Animals}

Thirty-six male C57BL/6 mice (body weight: $30 \pm 2$ g) were used at the age of 20 weeks. The mice had free access to food and water and were maintained on a 12$\mathrm{h}$ dark-light cycle in a controlled temperature room $\left(25^{\circ}\right.$ $\mathrm{C} \pm 2^{\circ} \mathrm{C}$ ) for the duration of the study. The animals were divided into three groups of twelve mice. In one group, mice were injected with tau oligomers and PBS; in a second group, mice were injected with tau fibrils and PBS; in the third group, mice were injected with tau monomers and PBS. All animal experiments were performed in accordance with IACUC approved protocols. 
Tau subcortical stereotaxic injection

We anesthetized male C57BL/6 mice with ketamine (10 $\mathrm{mg} / \mathrm{mL})$ and xylazine $(1.5 \mathrm{mg} / \mathrm{mL})$, and then positioned on a stereotaxic frame. Once we identified bregma and drilled holes in that location, $1 \mu \mathrm{L}$ of $0.9 \mathrm{mg} / \mathrm{mL}$ of various tau preparations and/or the same volume of PBS buffer were injected into the hippocampus in the left and right hemispheres, respectively $(-2.06 \mathrm{~mm}$ posterior, $+/-1.75 \mathrm{~mm}$ lateral, and $2.5 \mathrm{~mm}$ ventral to the bregma) at a rate of $0.2 \mu \mathrm{L} / \mathrm{min}$.

\section{Object recognition task}

Mice were tested in an open-square white arena, $60 \times$ $60 \mathrm{~cm}, 40 \mathrm{~cm}$ high. The following objects were used: a black metal cylinder, $6 \times 7 \mathrm{~cm}$; an orange disk, $1.5 \times 5$ $\mathrm{cm}$; and a plastic cube, $4 \times 4 \mathrm{~cm}$. The task started with a habituation trial, during which the animals were placed in the empty arena for $10 \mathrm{~min}$. The next day, mice were injected with the corresponding tau species and/or the vehicle (PBS). Twenty-four hours later, the mice were again placed in the same arena containing two identical objects (familiarization phase). Exploration was recorded in a 10-min trial. Sniffing, touching, and stretching the head toward the object at a distance of no more than $2 \mathrm{~cm}$ were scored as object investigation [29]. Six hours later (test phase), mice were again placed in the arena containing two objects: one identical to one of the objects presented during the familiarization phase (familiar object), and a new, different object (novel object). The time spent exploring the two objects was recorded for $10 \mathrm{~min}$. Memory was expressed as a discrimination index, namely (seconds on novel-seconds on familiar)/(seconds on novel + seconds on familiar) and was expressed as the percentage of time on each object. Animals with no memory impairment spend a longer time investigating the novel object compared with the familiar object, giving a higher discrimination index. At the end of the experiment, we euthanized the mice using cervical dislocation and dissected the brains of six animals per group. We then fixed these brains in $4 \%$ buffered paraformaldehyde, and embedded them in paraffin for histological analysis. The brains from the other six mice of each group were frozen for biochemical analysis.

\section{Western blot analysis}

We divided each brain into hemispheres and then the hippocampus was isolated and homogenized in ice-cold PBS with protease inhibitors $(5 \% \mathrm{w} / \mathrm{v})$. We centrifuged the homogenates for $10 \mathrm{~min}$ at $300 \mathrm{~g}$. Next, we quantified the proteins in the supernatant using a Bradford assay (Sigma, B6916) and separated equal amounts of them using an SDS-PAGE and then we transferred them onto nitrocellulose. After being blocked with non-fat dried milk, membranes were probed with anti-synaptophysin
(1:1000, Abcam, ab8049), anti-complex V d-subunit (1:2000, Invitrogen, 459000), anti-complex I subunit (1:1000, Invitrogen 459210), anti-caspase-9 (1:4000, Abcam, ab8087), anti-tubulin (1:1500, Oncogene, CP06), anti-synapsin-1 (1:3000, Abcam, ab8), anti-septin 11 (1:2000, Abcam, ab86268), anti-active caspase-3 (1:1000, Abcam, ab2302), and anti-caspase- 8 antibody (1:4000, Abcam, ab52183). The first five antibodies immunoreactivity was detected with horseradish peroxidase (HRP)-conjugated anti-mouse IgG (1:3000, Jackson ImmunoResearch Laboratories, Inc. West Grove, PA) and anti-rabbit IgG (1:3000, Jackson ImmunoResearch Laboratories, Inc., West Grove, PA) for other the four antibodies, followed by electrochemiluminescence (Thermo Scientific, Rockford, IL).

\section{Immunohistochemical and microscopic analysis}

Paraffin sections were deparaffinized, rehydrated, and washed in $0.01 \mathrm{~mol} / \mathrm{L}$ PBS for $5 \mathrm{~min}$., repeated three times. After blocking in normal goat serum for $1 \mathrm{~h}$, sections were incubated overnight with mouse monoclonal anti-synaptophysin antibody (predilute; Chemicon, IHCR1011-6) or mouse monoclonal (2-23) antibody to caspase-9 (1:200; Abcam, ab78087) or mouse monoclonal anti-NeuN antibody (1:1000, Chemicon, MAB377). The next day the sections were washed in PBS three times for $10 \mathrm{~min}$ and then incubated with goat antimouse IgG alexa488 (1:700; Invitrogen, A11004) for $1 \mathrm{~h}$. Later, we washed the sections three times for $10 \mathrm{~min}$ in PBS, and finally we applied VECTASHIELD mounting medium with DAPI staining (Vector Lab., H-1000) and the slide was coverslipped and sealed with clear nail polish. Double staining was performed, using the mouse monoclonal antibody HT7 (1:1000; Pierce, MN1000), which recognizes human tau (but not mouse tau) [50] and the rabbit polyclonal antibody anti-porin (1:500; Abcam, ab15895), a marker for mitochondria. The secondary antibodies goat anti-mouse IgG alexa488 (1:700; Invitrogen, A11004) and goat anti-rabbit IgG alexa568 (Invitrogen, A11036) were used to detect HT7 and antiporin, respectively. In order to determine degenerating neurons, we stained the sections with Fluoro-Jade B according to manufacturer specifications (Millipore, AG310). Next, we examined the brain sections using an epifluorescence microscope (Nikon Eclipse 800) equipped with a CoolSnap-FX monochrome CCD camera (Photometrics, Tucson, AZ) using a standard Nikon FITC and DAPI filters and acquired and analyzed the images using the Metavue V7.1 software (Molecular Devices, Downingtown, PA). To examine nuclear morphology and degeneration, we performed hematoxylin staining and acquired bright field images using a Nikon Multizoom AZ100 microscope equipped with a Nikon DS-2M color CCD camera (Nikon Instruments Inc, Melville, NY). 


\section{Intensity correlation analysis}

Intensity correlation analysis (ICA) is based on the principle that for any set of values the sum of the differences from the mean equals zero, i.e., $\Sigma_{\mathrm{N}}\left(A i_{-} a\right)=0$, where $a$ is the mean of the distribution with $N$ values of $A i$. In our case, $N$ is the number of pixels, and $A i$ is the staining intensity for each pixel. It follows that for $N$ pixels associated with two sets of random staining intensities $(A i$ and $B i)$, the sum of the product of their differences will also tend to zero; thus, $\Sigma_{\mathrm{N}}\left(A i_{-} a\right)\left(B i_{-} b\right) \approx$ 0 . However, this is not the case if the two intensities are dependent (when the product tends to be a positive value) or if they are segregated (when the product tends to be a negative value). Thus, with dependent staining $\Sigma_{\mathrm{N}}(A i-a)(B i-b)>0$, whereas with segregated staining $\Sigma_{\mathrm{N}}(A i-a)(B i-b)<0[51]$. We used this property to test for dependent or segregated staining between HT7 and anti-porin antibody. Analysis performed using Image-J software (National Institutes of Health).

\section{Statistical analysis}

For protein quantification, the densitometry of each band in the Western blot was normalized with tubulin. All densitometry results represent the mean and standard deviations of all of the determinations performed. Data were compared by one-way analysis of variance (ANOVA) followed by Bonferroni's multiple comparison test. The criterion for statistical significance between groups was $\mathrm{P}<0.001$. The same analysis was performed for the quantification of Fluoro-Jade B positive cells. In the case of the object recognition experiments, the discrimination index data was analyzed using one-way ANOVA, followed by a Tukey's post-hoc test. The criterion for statistical significance was $\mathrm{p}<0.01$. We analyzed the percent of time spent with each object using Student's t-test. Specifically the time spent with the novel object was compared with the time spent with the familiar object in the same group. The criterion for statistical significance was $\mathrm{p}<0.001$. All statistical analyses were performing using OriginPro 8.0 software.

\section{Results}

Tau oligomers impair memory encoding/consolidation C57BL/6 male mice received stereotaxic subcortical injections of either oligomeric, fibrillar, or monomeric tau in the right hemisphere and PBS buffer in the left hemisphere, a scheme summarized in Figure 1A, and then we tested the animals in the novel-object recognition task. To compare our methods with the standard heparin method, an additional control group was injected with tau fibrils prepared according the standard heparin protocol $[30,31]$. Figure $1 \mathrm{~B}$ shows the precise site of the injections, just above the CA1 region of the hippocampus. We chose this site for the injection according to previous studies that described large number of NFTs and extensive neuron loss from the CA1 region of the hippocampus in patients with $\mathrm{AD}$ in comparison with age-matched controls [32-35]. Tau oligomers and fibrils were characterized by AFM (Figure 1D, E and 1F), and the oligomers were purified by FPLC (Figure 1C) before injection. The oligomeric species molecular weight indicates that it represents a tau dimer/trimer, as previously described [36]. We injected the tau preparations and PBS into the C57BL/6 mice $24 \mathrm{~h}$ before training in an arena containing two objects that they could explore freely (familiarization phase). Six hours later, we exposed the mice to one familiar and one new object (test phase). Mice injected with tau oligomers were unable to distinguish the new object, with no significant difference in the percentage of time spent investigating both objects (Figure 2A), and displayed a discrimination index significantly lower than that of the other three groups (Figure 2B). Neither monomeric nor any of the fibrillar tau animals showed memory deficits in this task (Figure 2A and 2B). These data indicate that tau oligomers acutely disrupt anterograde memory storage, which parallels the anterograde memory deficits in early-stage AD patients who are unable to store newly-acquired information [37].

\section{Tau oligomers induced neuronal degeneration}

Next, we investigated the effects of different forms of tau in neuronal degeneration. We harvested the brains from six animals that underwent behavioral testing and then fixed them in $4 \%$ buffered paraformaldehyde, and embedded in paraffin. Cell damage was detected only in the group injected with tau oligomers and only in the CA1 region of the hippocampus in the right hemisphere (Figure 3A, E and 3I.

To determine cell damage, we performed nuclear staining using Hematoxylin (Figure 3A-D) and neuronal staining was performed using NeuN antibody (Figure $3 \mathrm{E}-\mathrm{H})$. In both cases, tau oligomers were highly toxic, producing great destruction of the pyramidal layer of neurons in the hippocampal region, underneath the injection site (Figure 3A and 3E). Tau fibrils also show some degree of toxicity, but much less than tau oligomers (Figure $3 \mathrm{~B}$ and $3 \mathrm{~F}$ ). We detected cell damage solely in the group injected with tau oligomers and only in the CA1 region of the hippocampus in the right hemisphere (Figure 3). None of the mice displayed any damage in the hippocampus of the left hemisphere (Figure 3D, H, and $3 \mathrm{~L}$ ), demonstrating that the toxicity produced by tau oligomers is located in the area of injection, even at least 30 hours post-injection. The oligomers that diffused to other areas of the hippocampus did not produce neuronal damage (Additional File 1, Figure 1), probably because of the low concentration of 


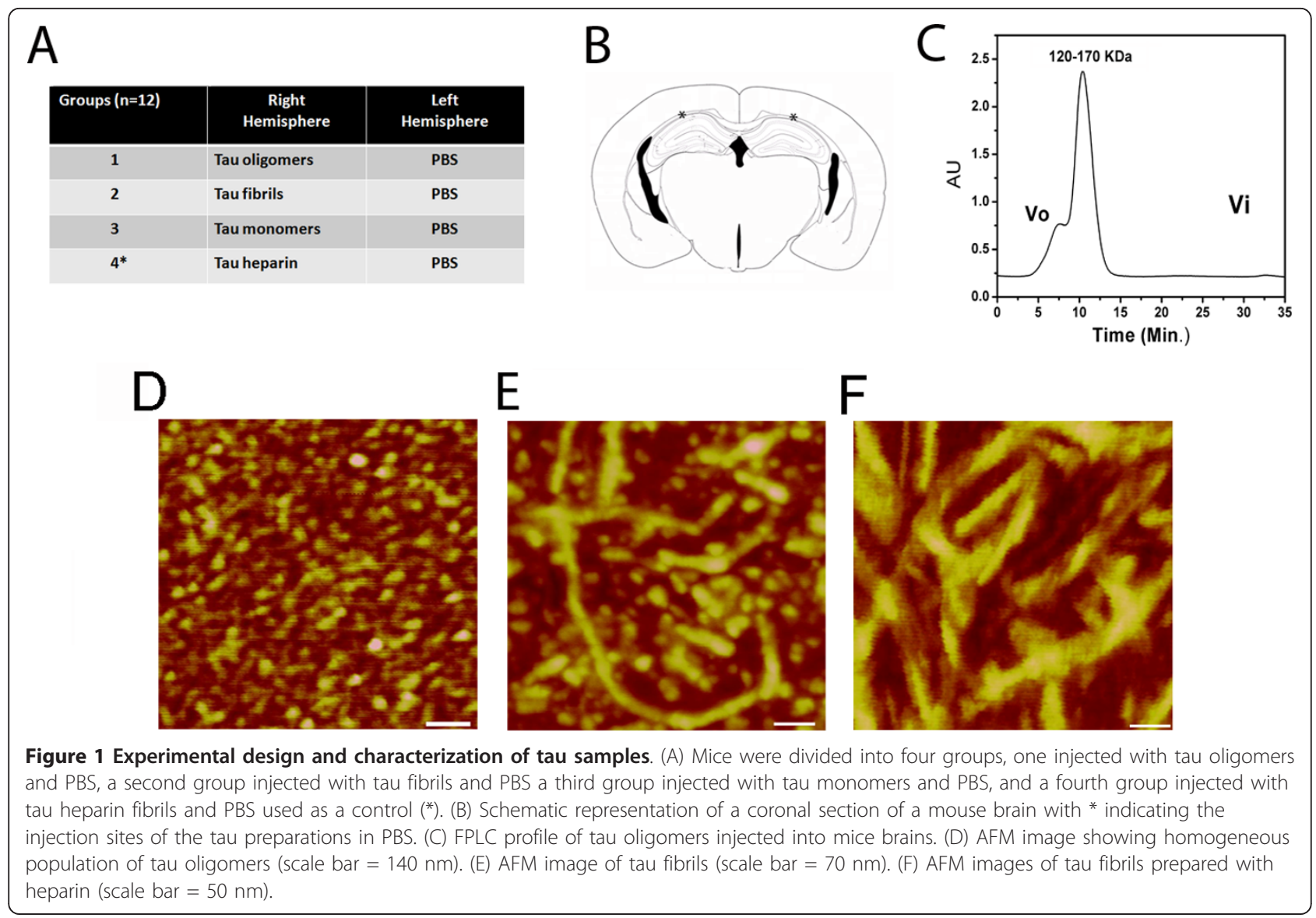

oligomers in these areas. To investigate neurodegeneration, we stained sections with Fluoro-Jade B, which is a fluorescein derivative that specifically labels dying neurons in the brain $[38,39]$. As seen in Figure 3, neurons exposed to tau oligomers exhibit intense Fluoro-Jade B labeling, which indicates a high level of neurodegeneration. It was also possible to see some labeling in the neurons treated with fibrils (Figure 3), but it is very low in comparison with the group treated with oligomeric tau. Fluoro-Jade B positive cells were counted and nearly

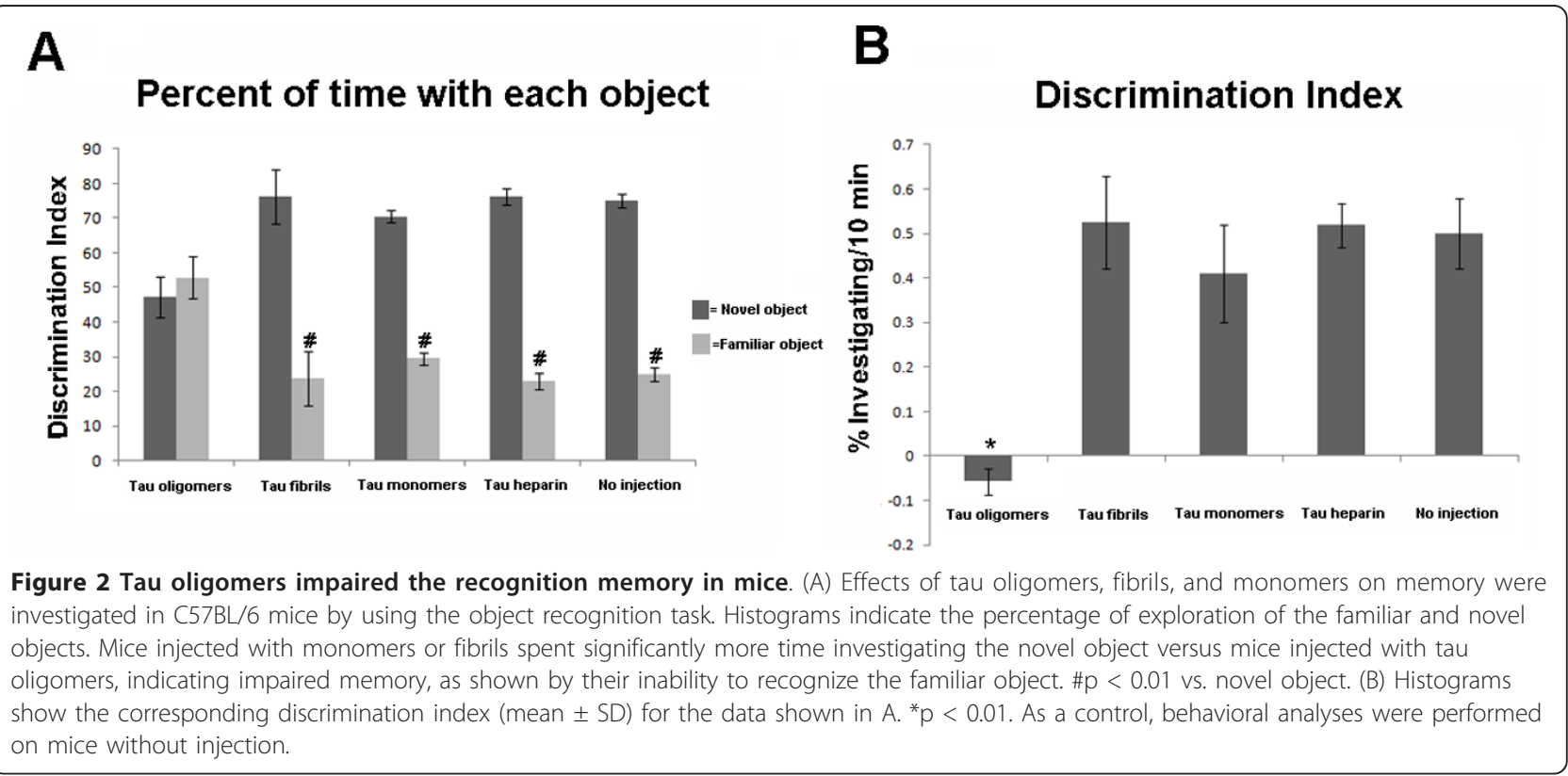




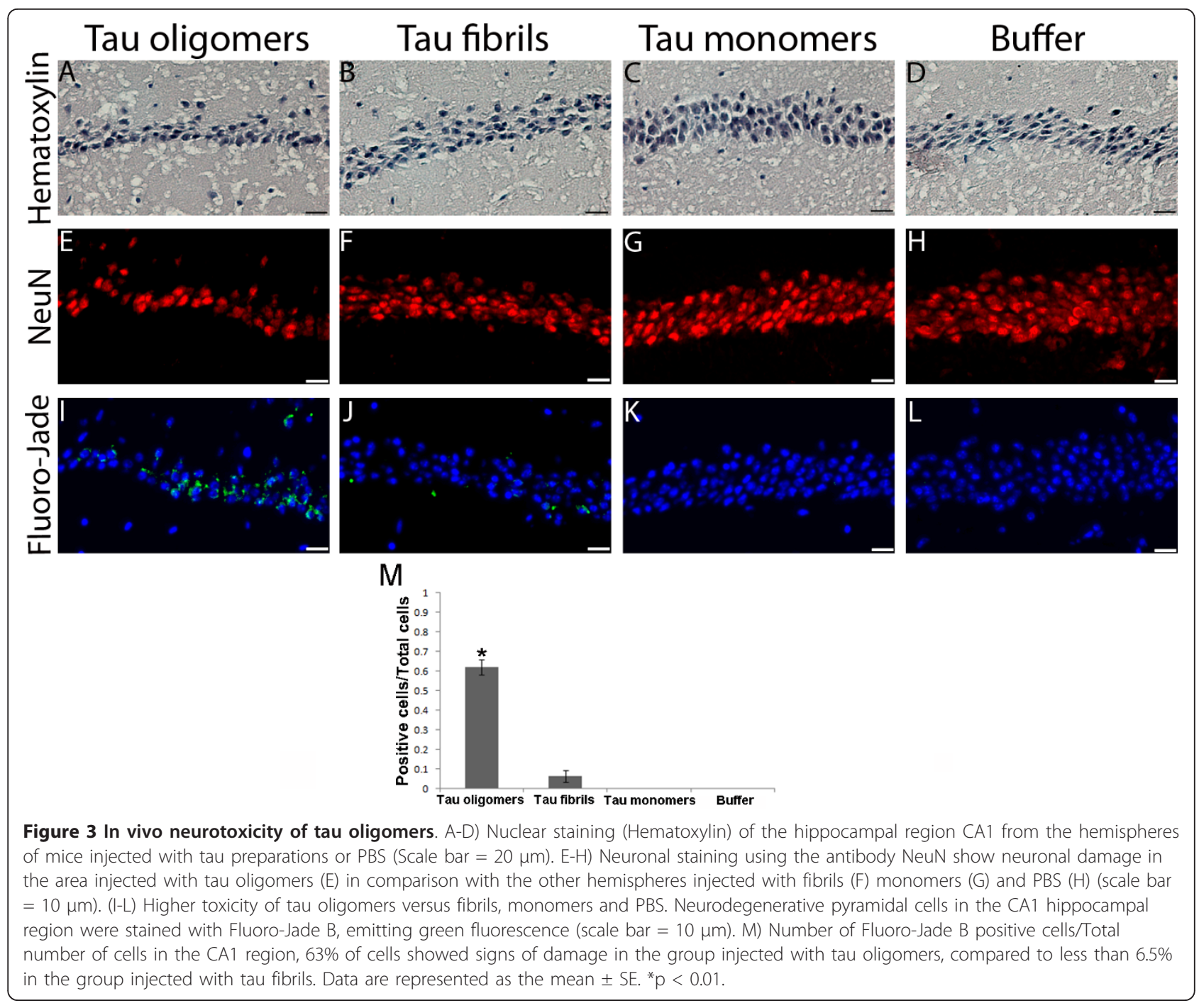

$60 \%$ of the neurons in the CA1 region, showed signs of damage in the group injected with tau oligomers, compared to less than $7 \%$ in the group injected with tau fibrils. Fluoro-Jade B binds to polyaminergic products of cellular degeneration, such as spermidine, cadaverine, and putrescine $[38,39]$. These data demonstrate that tau oligomers produce neuronal damage of the CA1 region of the hippocampus, which is also typical in patients with $\mathrm{AD}[34,35]$. Using these same parameters, we found that tau fibrils present some neuronal damage in vivo, but clearly lower damage than tau oligomers (Figure 3). The fact that tau fibrils present some toxicity may be because the fibrils were partially broken-down into smaller, oligomeric aggregates. In addition, we must take into consideration that the fibrils were directly prepared from tau oligomers, so there remains a possibility that the injected solution contained a small amount of tau oligomers and/or prefibrillar oligomers that could explain the detectable amount of toxicity. To elucidate this point, as we mentioned in the previous section, we injected into another group of mice tau fibrils $(0.9 \mathrm{mg} /$ $\mathrm{mL}$ ) prepared using the heparin protocol [30,31]. This is a well-described procedure to produce highly pure tau fibrils. Mice did not present any memory impairment (Figure 2) or Fluoro-Jade B positive staining (data not shown); suggesting that the mild cellular damage observed in the group injected with fibrils prepared from oligomers was due to the presence of oligomers in the preparation. Using the fibrils prepared with heparin showed no toxicity even when we injected twice the amount of tau fibrils by using the same volume at twice the original concentration of each tau species $(1.8 \mathrm{mg} / \mathrm{mL})$. As observed in the original experiments, only the mice injected with tau oligomers exhibited memory impairment (Additional File 1, Figure 2). These data suggest that the amount of oligomers in the tau fibrils is minimal; therefore, 
it has no considerable toxic effects and does not cause memory deficits in the mice.

\section{Loss of synaptic markers in mice injected with tau oligomers}

Early changes in AD brains include loss of synapses. This precedes the anomalous aggregation of protein (amyloid plaques, NFTs) and correlates with cognitive dysfunction [40,41]. The role of tau in this context has yet to be ascertained, but several studies using in vivo models gave evidence of the relevance of tau in synaptic loss and synaptic dysfunction [11]. In the P301S mutant human tau transgenic mice, Yoshiyama et al. detected loss of hippocampal synapses and impaired synaptic function [15]. A relevant point of that study is that synaptic dysfunction appears before the formation of NFTs, which gives evidence implicating synaptic pathology as an early neurotoxic consequence of pathogenic human tau expression culminating in progressive neurodegeneration [15]. In a recent study, Polydoro et al. showed through behavioral and electrophysiological experiments for the first time that an accumulation and aggregation of non-mutant tau isoforms might cause cognitive and synaptic dysfunction [14].

To assess the effect of different tau species on synapses using biochemical and histochemical analyses, we measured the levels of several proteins related to synaptic function. These proteins included the synaptic vesicle-associated proteins, synaptophysin, synapsin-1, and septin-11. Synaptophysin is a vesicle-bound presynaptic protein, synapsin-1 regulates the reserve pool of synaptic vesicles [42], and septin-11 is involved in vesicle trafficking and may play a role in synaptic connectivity. For biochemical analysis, Western blot assays were performed using the PBS-soluble brain fraction (six mice per group) and subsequently the relative amount of protein was quantified by densitometry and normalized with tubulin. We observed a clear decrease in synaptophysin in the group injected with tau oligomers in comparison with the other two groups (Figure 4B). We then confirmed this result by performing immunohistochemistry, where we saw a decrease of synaptophysin density in the CA1 region of the brain hemisphere injected with oligomers (Figure 5). No changes in synaptophysin level occurred in the brains injected with fibrils or monomers, or in any hemisphere injected with PBS. Thus, pre-synapses seem to be affected by tau oligomers in the CA1 region of the hippocampus. Similar to the synaptophysin measurements, the levels of septin-11 were significantly lower in the hemisphere injected with tau oligomers in comparison with the hemispheres injected with fibrils or monomers (Figure 4D). This result indicates that tau oligomers may affect trafficking and microtubule stability. In the case of synapsin-1, we observed no statistical differences in the levels of this protein between the different groups (Figure 4B). This result suggests that tau aggregates do not affect the maintenance of the reserve pool of synaptic vesicle. It is important to mention that in all measurements, with the three different synaptic markers, we did not observe any differences between any of the hemispheres injected with PBS and the hemispheres injected with tau monomers (Figure 4).

\section{Evidence of mitochondrial dysfunction in mice treated with tau oligomers}

In $\mathrm{AD}$, mitochondrial abnormalities occur early in the pathogenic process and likely play a significant role in disease progression. Several studies have demonstrated markedly reduced levels of mitochondrial proteins and activity [43-45] in the brains of AD patients. Recently, using transgenic mice overexpressing the P301L mutant human tau protein, David et al. demonstrated mitochondrial dysfunction by proteomic and functional analysis [46]. Specifically, they demonstrated reduced NADHubiquinone oxidoreductase (complex I) activity and impairment of mitochondrial respiration, and ATP synthesis (complex V) with age in P301L mice. Quintanilla et al. demonstrated that inducible expression of tau truncated at Asp-421, to mimic caspase cleavage, induced mitochondrial fragmentation and loss of mitochondrial membrane integrity [47]. In this study, we examined the relationship between possible pathological forms of tau and mitochondrial dysfunction.

Studies that correlate the stage of aggregation of tau with mitochondrial abnormalities are in short supply. For this reason, we measured the levels of mitochondrial complexes I and V in all groups. We saw decreased levels of $\mathrm{NADH}$-ubiquinone oxidoreductase (electron transport chain complex I) in the hemispheres injected with tau oligomers in comparison with the ones injected with fibrils or monomers (Figure 6B). This result correlates with previous studies of $A D$ brains, suggesting that modifications of mitochondrial encoded complex I subunit mRNA $[48,49]$, reduction in protein levels of the $24-$ and $75-\mathrm{kDa}$ subunits of complex I [45], and other mitochondrial dysfunction effects [46] can arise owing to tau accumulation in the absence of massive formation of NFTs. In the case of complex V levels, we did not observe any statistical difference between any of the groups (Figure 6C), demonstrating that tau oligomers do not acutely affect the initial state of ATP synthesis. Our results suggest that tau oligomers initially affect complex I activity and complex $\mathrm{V}$ could also be affected in a later state directly or indirectly by the action of tau oligomers.

The fate of injected tau oligomers was investigated (Figure 6E-H), double staining using the mouse monoclonal antibody HT7 (Figure 6E), which recognizes human 


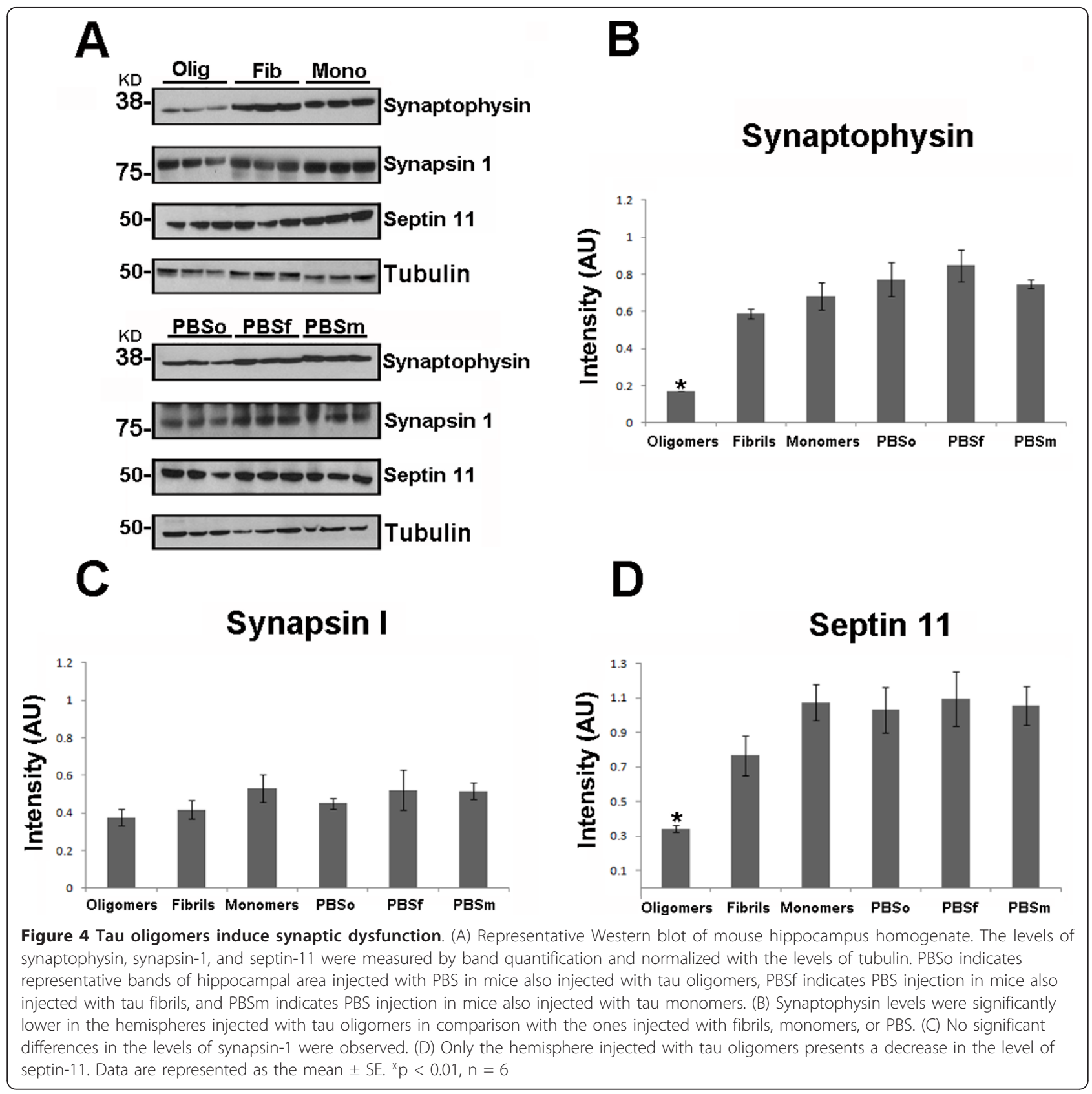

tau but not murine tau [50], and anti-porin antibody, as a marker for mitochondria (Figure 6F); co-localization between tau oligomers and mitochondria in CA1 cells (Figure 6G);. This was confirmed by ICA of the signal (Figure 6H), as described in [51], suggesting a direct interaction between tau oligomers and mitochondria.

Neuronal commitment to apoptosis may occur through a mitochondrial pathway employing caspase- 9 or through an alternative, receptor-mediated pathway involving caspase-8 [52]. Considering the role of mitochondrial dysfunction in $\mathrm{AD}$, we examined the possible activation of caspase- 9 by using an antibody that recognizes the active fragment of caspase-9. Western blot analysis demonstrated a considerable activation of caspase-9 in the hemispheres injected with tau oligomers (Figure 6D). By using immunohistochemistry techniques, we confirmed that the activation of caspase- 9 is mainly in the hemispheres injected with tau oligomers and in varying levels in the hemispheres injected with fibrils, which was not statistically significant according to the biochemical analysis. We did not observe caspase-9 activation in the hemispheres injected with the monomer or PBS (Figure 7). These results are supported by a recent study demonstrating a closer association 

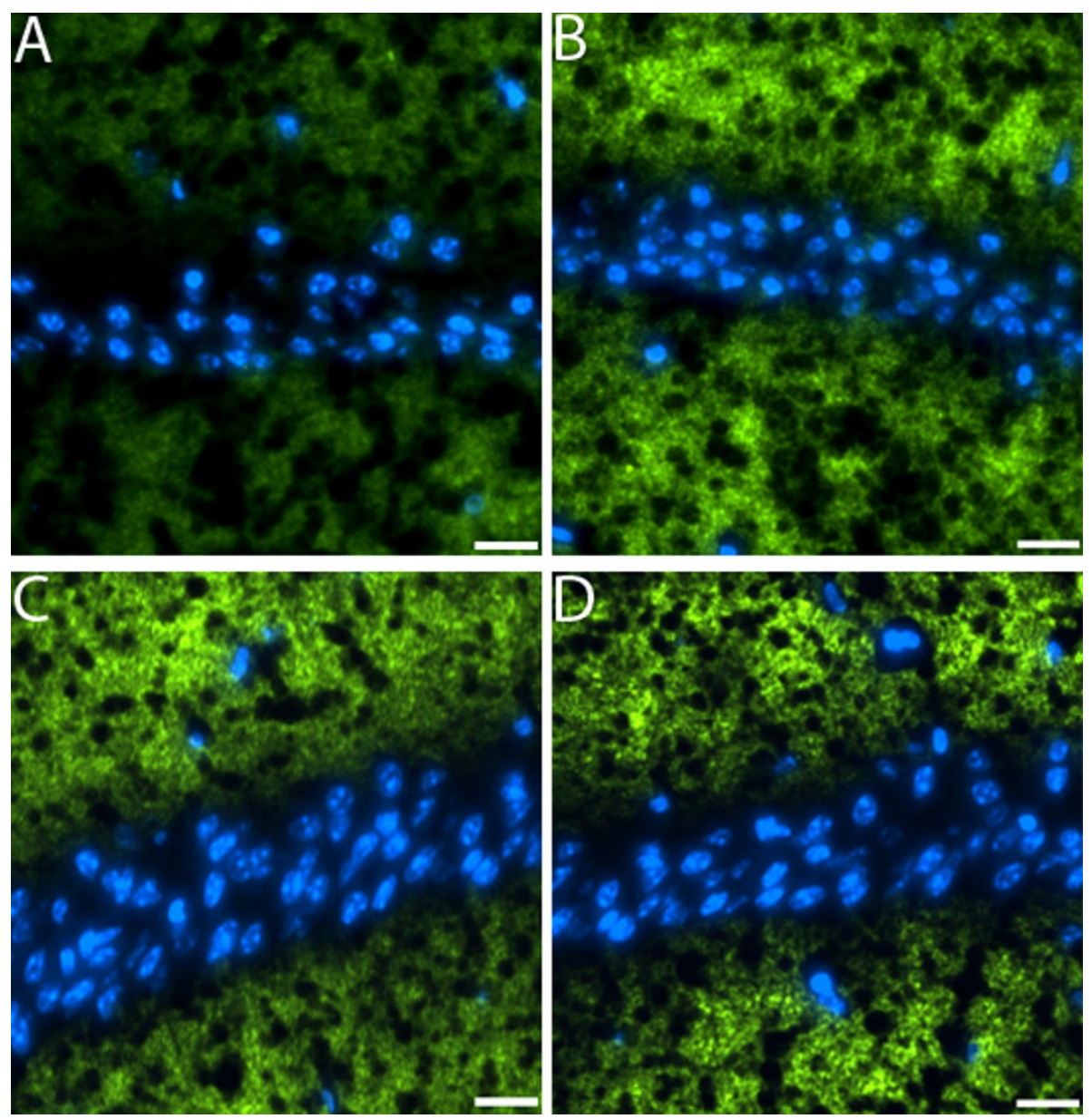

Figure 5 Decrease in synaptophysin in mice injected with tau oligomers. Brain sections were stained with antibody to the presynaptic marker synaptophysin (green) nuclear staining with DAPI (blue). All images were taken from the CA1 region. Hemispheres injected with tau oligomers exhibited a decreased in synaptophysin (A). No decrease in the signal was observed in the hemispheres injected with fibrils (B), monomers (C), and PBS (D). (Scale bars $=10 \mu \mathrm{m}$.)

between the formation of NFTs than $A \beta$ deposits in the activation of caspase-9. Moreover, the same study concludes that the activation of caspase- 9 precedes tangle formation [53]. We also did not detect caspase-8 activation in our study (data not shown).

\section{Discussion}

The role of soluble oligomeric forms of disease-associated protein has received considerable attention in several neurodegenerative diseases because of their association with toxicity [54-56]. There is a growing belief that intermediates in the formation of NFTs encompass the pathogenic forms of tau [11,16,20,57-59]. Herein, we demonstrated that tau oligomers injected in proximity of the hippocampus were responsible for immediate memory impairment in mice by acutely disrupting anterograde memory storage. These observations correlate with previous studies in humans and primates that have shown hippocampal lesions to result in impaired object recognition $[60,61]$. The neuronal damage produced by tau oligomers in the CA 1 region is consistent with previous work, which shows that neurodegeneration in CA1 region occurs prior to the formation of NFTs and the clinical diagnosis of dementia in $\mathrm{AD}$ patients [62]. This suggests that tau oligomers could be responsible for neuronal death in the CA1 region in $\mathrm{AD}$ or other tauopathies. In the specific case of $\mathrm{AD}$, NFTs progressively spread throughout the brain in an anatomically stereotypical manner [63,64]. Based on these and several other studies, it has been postulated that tau proteins spread in a prion-like mechanism in the tauopathies [65-67]. Clavaguera et al.'s observations support this concept by demonstrating that intracerebral injections of brain extract from mice with a filamentous tau pathology (P301S mutation) induces the formation and spreading of tau aggregates. The pathology spread 

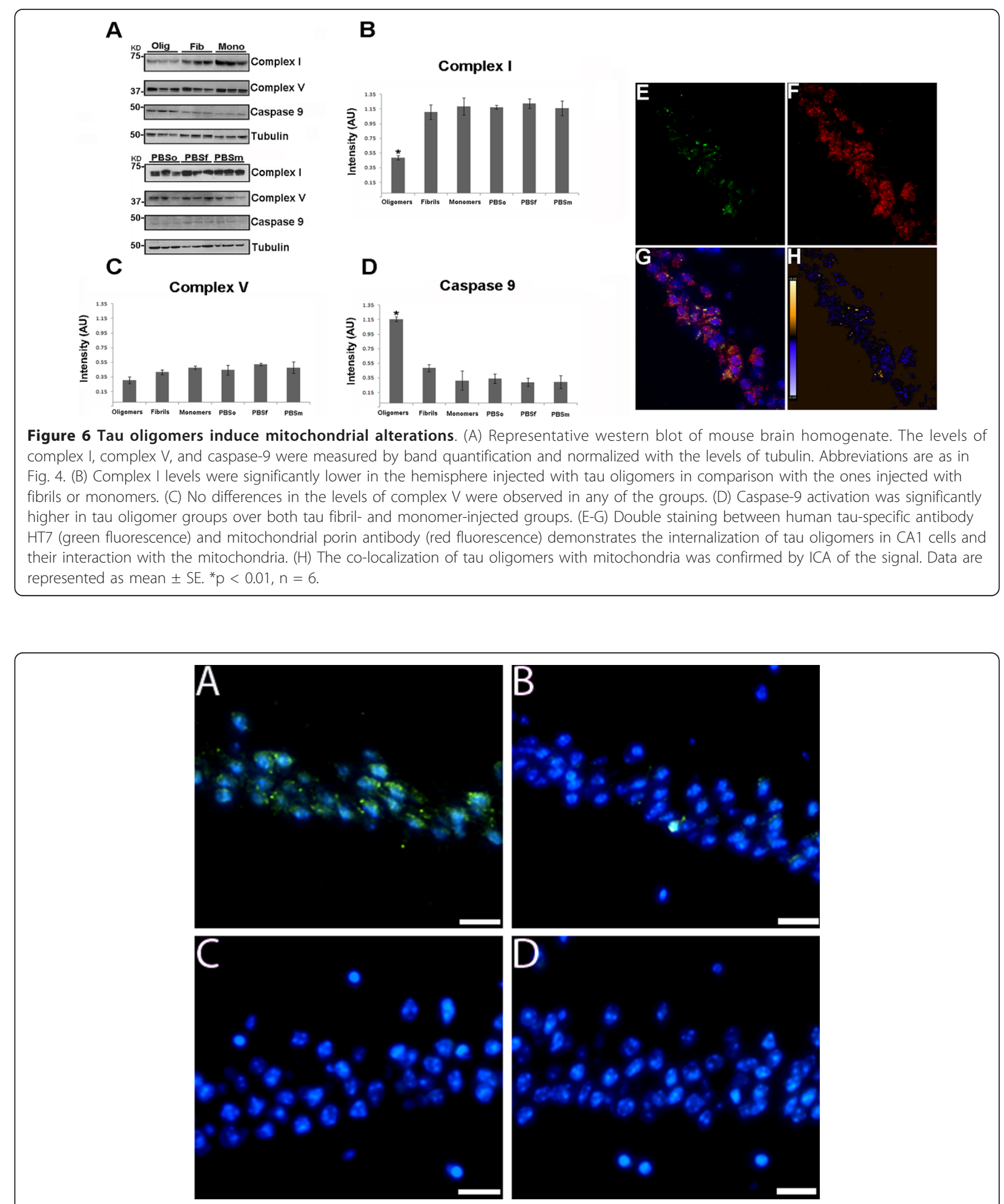

Figure 7 Caspase-9 activation in hemisphere injected with tau oligomers. Immunofluorescence using an antibody for pro-caspase-9 was performed. (A and B) Caspase-9 activation (green fluorescence) was observed in hemispheres injected with tau oligomers (A) or fibrils (B). However, the levels of activation were significantly higher in the hemispheres injected with oligomers compared with fibrils, which is not significant. (C and D). No activation of caspase-9 was observed in the hemispheres injected with tau monomers (C) or PBS (D). Nucleus was stained with DAPI (blue). (Scale bars $=10 \mu \mathrm{m}$.). 
from the injection site to neighboring brain regions 15 months post-injection in transgenic mice for human wild-type tau (ALZ17 mouse model) [66] and 12 months post-injection in wild-type mice.

The neurodegeneration produced by tau oligomers occurred exclusively in the regions at the injection site (CA1 region). In future studies it will be necessary to establish several time points and work with transgenic mouse models that express tau in order to determine if tau oligomers induce endogenous tau aggregation and spread into further areas of the brain. Nevertheless, our results are in accordance with previous in vitro studies that reveal extracellular tau to be toxic to neuronal cells, and aggregated tau to be capable of propagation from the outside to the inside of a cell [68-70]. On the basis of their results, Gomez-Ramos et al. suggested that NFTs, or other compounds released by degenerating neurons, may accumulate in the extracellular space and this could be toxic to the surrounding cells [68]. Frost et al. showed that cultured cells take up extracellular aggregated tau, but not monomers, and that the internalized tau aggregates induce fibrillization of intracellular tau. Moreover, they observed that newly aggregated intracellular tau transfers between co-cultured cells [69]. If we take into consideration these studies and the novel data presented in our study, we can postulate that tau oligomers generated intracellularly could be released either by binding and local rupture of the membrane, or after cell death. The oligomers in the extracellular space could be taken-up by healthy neurons in the vicinity disrupt normal activity and stimulate further aggregation of functional monomeric tau. Our results show that tau oligomers are co-localized with mitochondria and display intraneuronal punctuate staining with HT7 antibody, indicative of the internalization of injected tau oligomers.

Others in the field propose that a connection between tau pathology and mitochondrial impairment is prevalent $[46,47]$. Several studies suggest that in AD, mitochondrial abnormalities occur early in the pathogenic process and likely play a significant role in disease progression. In our study, we observed that the injected oligomers co-localized with the mitochondrial marker porin, providing further evidence of a pathological relation between oligomeric tau and mitochondrial dysfunction. Tau oligomers may impair microtubule stability and trafficking, which can affect the distribution of various organelles, including mitochondria. Mitochondria travel for long distances to fulfill the high-energy demand of synapses; thus, inhibition of transport disrupts the supply lines for energy. An alternative approach of how tau can affect synapses could be the direct inhibition of energy production through the mitochondria in the synapses. We found decreased levels of complex I in the hemispheres injected with tau oligomers as compared with the brains injected with fibrils or monomers. This decrease in complex I may lead to severe energy impairments in synapses, as a reduction in the activity of complex I of only $25 \%$ impairs energy metabolism in synaptic mitochondria [71], whereas a reduction of complex I activity by $72 \%$ is necessary to impair energy metabolism in non-synaptic mitochondria [72]. We did not observe statistical significances in complex $\mathrm{V}$ levels between any of the groups. This relates well with the data presented by David et al., where age affects complex $\mathrm{V}$, but decreases in complex I occur early in the disease process [46], suggesting tau oligomers could affect complex $\mathrm{V}$ in a later stage of pathology, either directly or indirectly. Overall, according to our results, we can postulate that tau oligomers inhibit energy production through complex I, which can produce synaptic alterations in synaptic-localized mitochondria.

In AD brains loss of synapses precedes NFTs formation and correlates with cognitive dysfunction [40,41]. Even though the role of tau in this context remains unclear, in studies of other models of tauopathies and in several tau mouse models $[14,15]$, the authors reported synaptic damage [73-75]. A recent study showed that missorting of tau in neurons causes degeneration of synapses, and the authors suggest that synaptic decay could be caused by some oligomeric form of tau that is not currently well defined [76]. Moreover, a very recent study by Kimura et al. demonstrated that in wild-type tau Tg mice, an early stage of tau aggregation (sarkosylsoluble) produced synaptic loss and memory impairment [77]. To further investigate synaptic alternations, we measured levels of characterized synaptic markers: synaptophysin and septin-11, which are involved in synaptic vesicle docking and trafficking, and synapsin-1, which is associated with the vesicle reserve pool. We found that only tau oligomers caused a decrease in synaptophysin and septin-11; however, no difference existed in the levels of synapsin-1 between all the groups. These results suggest that tau oligomers can affect presynaptic density and neuronal trafficking, but do not interfere with the reserved pool of synaptic vesicles. Another effect of mitochondrial dysfunction is the activation of the mitochondrial apoptotic pathway, measured by activation of caspase-9. We measured an increase in caspase- 9 activation in the hemispheres injected with tau oligomers, but not in the PBS-injected hemispheres. Earlier studies demonstrated the presence of activated caspase-9 in synaptosomal preparation of AD brains [78]. A possible explanation for the caspase activation could be that tau oligomers accumulate at the mitochondrial membrane, resulting in the release of cytochrome $C$, which leads to caspase- 9 activation through a complex with apoptotic peptidase activating factor-1 (Apaf-1) [79]. This mechanism has been suggested for other amyloidogenic proteins 
such as $\alpha$-synuclein, $A \beta$, and $\operatorname{PrP}[80,81]$. Even more, recently de Calignon et al, demonstrated that caspase activation precedes NFTs formation, suggesting that soluble tau species, rather than fibrillar tau, may be the critical toxic moiety underlying neurodegeneration [82].

The field of tau oligomers and other pre-filament tau aggregates is becoming an extremely important area of research in neurodegenerative diseases. Thus, understanding the negative impact of tau oligomers in neuronal damage, specifically in reference to important cellular mechanisms, such as mitochondrial and synaptic function, will likely be of great importance to understand the relevant disease processes and progression in $\mathrm{AD}$ and other tauopathies. These results support the hypothesis that tau oligomers are the acutely toxic species in tau aggregation, and the disruption of mitochondrial membrane, the activation of the apoptotic-related caspase-9, and reduction in complex I levels can cause this toxicity, leading to the inhibition of synaptic energy production due to tau oligomers. These cellular dysfunctions may underlie the synaptic dysfunction and memory impairments observed with tau oligomers in this study.

\section{Additional material}

Additional file 1: Supplementary Data

\begin{abstract}
Acknowledgements
Supported by the Cullen Trust, the Alzheimer's Drug Discovery foundation (ADDF), and the Mitchell Center for Neurodegenerative Diseases. We thank Dr. Bridget E. Hawkins for her suggestions and critical reading of the manuscript. We are grateful to Prof. Martin Margittai for providing recombinant tau and plasmid, and Dr. Marcos Guerrero-Munoz for his help in the purification and characterization of tau oligomers.
\end{abstract}

\section{Authors' contributions}

RK and $C L$ designed the experiments. $C L, D C, A C$ and US performed the experiments. RK, CL prepared the figures and analyzed the data. $C L, G J$ and RK wrote the paper. All authors read and approved the final manuscript.

\section{Competing interests}

RK is the founder of Conlmm, Inc. and has patent applications on the compositions, methods and reagents related to tau oligomers.

Received: 4 April 2011 Accepted: 6 June 2011 Published: 6 June 2011

\section{References}

1. Binder LI, Frankfurter A, Rebhun LI: The distribution of tau in the mammalian central nervous system. J Cell Biol 1985, 101:1371-1378.

2. Drechsel DN, Hyman AA, Cobb MH, Kirschner MW: Modulation of the dynamic instability of tubulin assembly by the microtubule-associated protein tau. Mol Biol Cell 1992, 3:1141-1154.

3. Lee VM, Goedert M, Trojanowski JQ: Neurodegenerative tauopathies. Annu Rev Neurosci 2001, 24:1121-1159.

4. Alonso AC, Li B, Grundke-lqbal I, lqbal K: Mechanism of tau-induced neurodegeneration in Alzheimer disease and related tauopathies. Curr Alzheimer Res 2008, 5:375-384.

5. Iqbal K, Liu F, Gong CX, Alonso AD, Grundke-labal I: Mechanisms of tauinduced neurodegeneration. Acta Neuropathol 2009, 118:53-69.
6. Ballatore C, Lee VM, Trojanowski JQ: Tau-mediated neurodegeneration in Alzheimer's disease and related disorders. Nat Rev Neurosci 2007, 8:663-672.

7. Haroutunian V, Davies P, Vianna C, Buxbaum JD, Purohit DP: Tau protein abnormalities associated with the progression of alzheimer disease type dementia. Neurobiol Aging 2007, 28:1-7.

8. Braak H, Braak E: Neuropathological stageing of Alzheimer-related changes. Acta Neuropathol 1991, 82:239-259.

9. Delacourte A, Buee L: Tau pathology: a marker of neurodegenerative disorders. Curr Opin Neurol 2000, 13:371-376.

10. Braak H, Alafuzoff I, Arzberger T, Kretzschmar H, Del Tredici K: Staging of Alzheimer disease-associated neurofibrillary pathology using paraffin sections and immunocytochemistry. Acta Neuropathol 2006, 112:389-404.

11. Brunden KR, Trojanowski JQ, Lee VM: Evidence that non-fibrillar tau causes pathology linked to neurodegeneration and behavioral impairments. J Alzheimers Dis 2008, 14:393-399.

12. Marx J: Alzheimer's disease. A new take on tau. Science 2007, 316:1416-1417.

13. Andorfer C, Acker CM, Kress Y, Hof PR, Duff K, Davies P: Cell-cycle reentry and cell death in transgenic mice expressing nonmutant human tau isoforms. J Neurosci 2005, 25:5446-5454.

14. Polydoro M, Acker CM, Duff K, Castillo PE, Davies P: Age-dependent impairment of cognitive and synaptic function in the htau mouse model of tau pathology. J Neurosci 2009, 29:10741-10749.

15. Yoshiyama Y, Higuchi M, Zhang B, Huang SM, Iwata N, Saido TC, Maeda J, Suhara T, Trojanowski JQ, Lee VM: Synapse loss and microglial activation precede tangles in a P301S tauopathy mouse model. Neuron 2007, 53:337-351.

16. Berger Z, Roder H, Hanna A, Carlson A, Rangachari V, Yue M, Wszolek Z, Ashe K, Knight J, Dickson D, Andorfer C, Rosenberry TL, Lewis J, Hutton M, Janus C: Accumulation of pathological tau species and memory loss in a conditional model of tauopathy. J Neurosci 2007, 27:3650-3662.

17. Spires TL, Orne JD, SantaCruz K, Pitstick R, Carlson GA, Ashe KH, Hyman BT: Region-specific dissociation of neuronal loss and neurofibrillary pathology in a mouse model of tauopathy. Am J Pathol 2006, 168:1598-1607.

18. Gomez-Isla T, Hollister R, West H, Mui S, Growdon JH, Petersen RC, Parisi JE, Hyman BT: Neuronal loss correlates with but exceeds neurofibrillary tangles in Alzheimer's disease. Ann Neurol 1997, 41:17-24.

19. Terry RD: Do neuronal inclusions kill the cell? J Neural Transm Suppl 2000, 59:91-93.

20. Maeda S, Sahara N, Saito Y, Murayama M, Yoshiike Y, Kim H, Miyasaka T, Murayama S, Ikai A, Takashima A: Granular tau oligomers as intermediates of tau filaments. Biochemistry 2007, 46:3856-3861.

21. Maeda S, Sahara N, Saito Y, Murayama S, Ikai A, Takashima A: Increased levels of granular tau oligomers: an early sign of brain aging and Alzheimer's disease. Neurosci Res 2006, 54:197-201.

22. Yamazaki M, Hasegawa M, Mori O, Murayama S, Tsuchiya K, Ikeda K, Chen KM, Katayama Y, Oyanagi K: Tau-positive fine granules in the cerebral white matter: a novel finding among the tauopathies exclusive to parkinsonism-dementia complex of Guam. J Neuropathol Exp Neurol 2005, 64:839-846.

23. Neumann K, Farias G, Slachevsky A, Perez P, Maccioni RB: Human Platelets Tau: A Potential Peripheral Marker for Alzheimer's Disease. J Alzheimers Dis

24. Congdon EE, Kim S, Bonchak J, Songrug T, Matzavinos A, Kuret J: Nucleation-dependent tau filament formation: the importance of dimerization and an estimation of elementary rate constants. J Biol Chem 2008, 283:13806-13816.

25. Xu S, Brunden KR, Trojanowski JQ, Lee VM: Characterization of tau fibrillization in vitro. Alzheimers Dement 2010, 6:110-117.

26. Huang SM, Mouri A, Kokubo H, Nakajima R, Suemoto T, Higuchi M, Staufenbiel M, Noda Y, Yamaguchi H, Nabeshima T, Saido TC, Iwata N: Neprilysin-sensitive synapse-associated amyloid-beta peptide oligomers impair neuronal plasticity and cognitive function. J Biol Chem 2006, 281:17941-17951.

27. Mouri A, Noda Y, Hara H, Mizoguchi H, Tabira T, Nabeshima T: Oral vaccination with a viral vector containing Abeta cDNA attenuates agerelated Abeta accumulation and memory deficits without causing inflammation in a mouse Alzheimer model. FASEB J 2007, 21:2135-2148.

28. Scholtzova H, Wadghiri YZ, Douadi M, Sigurdsson EM, Li YS, Quartermain D, Banerjee P, Wisniewski T: Memantine leads to behavioral improvement 
and amyloid reduction in Alzheimer's-disease-model transgenic mice shown as by micromagnetic resonance imaging. J Neurosci Res 2008, 86:2784-2791.

29. Zhang L, Xing Y, Ye CF, Ai HX, Wei HF, Li L: Learning-memory deficit with aging in APP transgenic mice of Alzheimer's disease and intervention by using tetrahydroxystilbene glucoside. Behav Brain Res 2006, 173:246-254.

30. Margittai M, Langen R: Template-assisted filament growth by parallel stacking of tau. Proc Natl Acad Sci USA 2004, 101:10278-10283.

31. Perez M, Valpuesta JM, Medina M, Montejo de Garcini E, Avila J: Polymerization of tau into filaments in the presence of heparin: the minimal sequence required for tau-tau interaction. J Neurochem 1996, 67:1183-1190

32. Ball MJ: Neurofibrillary tangles in the dementia of "normal pressure" hydrocephalus. Can J Neurol Sci 1976, 3:227-235

33. Bondareff W, Mountjoy CQ, Roth M, Hauser DL: Neurofibrillary degeneration and neuronal loss in Alzheimer's disease. Neurobiol Aging 1989, 10:709-715.

34. West MJ, Coleman PD, Flood DG, Troncoso JC: Differences in the pattern of hippocampal neuronal loss in normal ageing and Alzheimer's disease. Lancet 1994, 344:769-772.

35. West MJ, Kawas CH, Martin LJ, Troncoso JC: The CA1 region of the human hippocampus is a hot spot in Alzheimer's disease. Ann N Y Acad Sci 2000 908:255-259.

36. Lasagna-Reeves CA, Castillo-Carranza DL, Guerrero-Muoz MJ, Jackson GR, Kayed R: Preparation and characterization of neurotoxic tau oligomers. Biochemistry 2010, 49:10039-10041.

37. Greene JD, Baddeley AD, Hodges JR: Analysis of the episodic memory deficit in early Alzheimer's disease: evidence from the doors and people test. Neuropsychologia 1996, 34:537-551.

38. Schmued LC, Hopkins KJ: Fluoro-Jade B: a high affinity fluorescent marker for the localization of neuronal degeneration. Brain Res 2000, 874:123-130.

39. Schmued LC, Hopkins KJ: Fluoro-Jade: novel fluorochromes for detecting toxicant-induced neuronal degeneration. Toxicol Pathol 2000, 28:91-99.

40. Terry RD, Masliah E, Salmon DP, Butters N, DeTeresa R, Hill R, Hansen LA Katzman R: Physical basis of cognitive alterations in Alzheimer's disease: synapse loss is the major correlate of cognitive impairment. Ann Neurol 1991, 30:572-580.

41. Coleman PD, Yao PJ: Synaptic slaughter in Alzheimer's disease. Neurobiol Aging 2003, 24:1023-1027.

42. Gitler D, Takagishi Y, Feng J, Ren Y, Rodriguiz RM, Wetsel WC, Greengard P, Augustine GJ: Different presynaptic roles of synapsins at excitatory and inhibitory synapses. J Neurosci 2004, 24:11368-11380.

43. Mutisya EM, Bowling AC, Beal MF: Cortical cytochrome oxidase activity is reduced in Alzheimer's disease. J Neurochem 1994, 63:2179-2184.

44. Schagger $\mathrm{H}, \mathrm{Ohm} \mathrm{TG}$ : Human diseases with defects in oxidative phosphorylation. 2. F1F0 ATP-synthase defects in Alzheimer disease revealed by blue native polyacrylamide gel electrophoresis. Eur J Biochem 1995, 227:916-921.

45. Kim SH, Vlkolinsky R, Cairns N, Fountoulakis M, Lubec G: The reduction of $\mathrm{NADH}$ ubiquinone oxidoreductase 24- and 75-kDa subunits in brains of patients with Down syndrome and Alzheimer's disease. Life Sci 2001, 68:2741-2750.

46. David DC, Hauptmann S, Scherping I, Schuessel K, Keil U, Rizzu P, Ravid R, Drose S, Brandt U, Muller WE, Eckert A, Götz J: Proteomic and functional analyses reveal a mitochondrial dysfunction in P301L tau transgenic mice. J Biol Chem 2005, 280:23802-23814.

47. Quintanilla RA, Matthews-Roberson TA, Dolan PJ, Johnson GV: Caspasecleaved tau expression induces mitochondrial dysfunction in immortalized cortical neurons: implications for the pathogenesis of Alzheimer disease. J Biol Chem 2009, 284:18754-18766.

48. Sims NR, Finegan JM, Blass JP, Bowen DM, Neary D: Mitochondrial function in brain tissue in primary degenerative dementia. Brain Res 1987, 436:30-38

49. Aksenov MY, Tucker HM, Nair P, Aksenova MV, Butterfield DA, Estus S, Markesbery WR: The expression of several mitochondrial and nuclear genes encoding the subunits of electron transport chain enzyme complexes, cytochrome c oxidase, and NADH dehydrogenase, in different brain regions in Alzheimer's disease. Neurochem Res 1999, 24:767-774.

50. Mercken $M$, Vandermeeren M, Lubke U, Six J, Boons J, Vanmechelen E, Van de Voorde A, Gheuens J: Affinity purification of human tau proteins and the construction of a sensitive sandwich enzyme-linked immunosorbent assay for human tau detection. J Neurochem 1992, 58:548-553.

51. Li Q, Lau A, Morris TJ, Guo L, Fordyce CB, Stanley EF: A syntaxin 1, Galpha (o), and N-type calcium channel complex at a presynaptic nerve terminal: analysis by quantitative immunocolocalization. J Neurosci 2004 24:4070-4081.

52. Ashkenazi A, Dixit VM: Apoptosis control by death and decoy receptors. Curr Opin Cell Biol 1999, 11:255-260.

53. Rohn TT, Rissman RA, Davis MC, Kim YE, Cotman CW, Head E: Caspase- 9 activation and caspase cleavage of tau in the Alzheimer's disease brain. Neurobiol Dis 2002, 11:341-354.

54. Haass C, Selkoe DJ: Soluble protein oligomers in neurodegeneration: lessons from the Alzheimer's amyloid beta-peptide. Nat Rev Mol Cell Biol 2007, 8:101-112.

55. Glabe CG: Common mechanisms of amyloid oligomer pathogenesis in degenerative disease. Neurobiol Aging 2006, 27:570-575.

56. Caughey B, Baron GS, Chesebro B, Jeffrey M: Getting a grip on prions: oligomers, amyloids, and pathological membrane interactions. Annu Rev Biochem 2009, 78:177-204.

57. Santacruz K, Lewis J, Spires T, Paulson J, Kotilinek L, Ingelsson M, Guimaraes A, DeTure M, Ramsden M, McGowan E, Forster C, Yue M, Orne J, Janus C, Mariash A, Kuskowski M, Hyman B, Hutton M, Ashe KH: Tau suppression in a neurodegenerative mouse model improves memory function. Science 2005, 309:476-481

58. Mocanu MM, Nissen A, Eckermann K, Khlistunova I, Biernat J, Drexler D, Petrova O, Schonig K, Bujard H, Mandelkow E, Zhou L, Rune G, Mandelkow EM: The potential for beta-structure in the repeat domain of tau protein determines aggregation, synaptic decay, neuronal loss, and coassembly with endogenous Tau in inducible mouse models of tauopathy. J Neurosci 2008, 28:737-748.

59. Kayed R, Jackson GR: Prefilament tau species as potential targets for immunotherapy for Alzheimer disease and related disorders. Curr Opin Immunol 2009, 21:359-363.

60. Reed JM, Squire LR: Impaired recognition memory in patients with lesions limited to the hippocampal formation. Behav Neurosci 1997, 111:667-675.

61. Zola SM, Squire LR, Teng E, Stefanacci L, Buffalo EA, Clark RE: Impaired recognition memory in monkeys after damage limited to the hippocampal region. J Neurosci 2000, 20:451-463.

62. Kril JJ, Patel S, Harding AJ, Halliday GM: Neuron loss from the hippocampus of Alzheimer's disease exceeds extracellular neurofibrillary tangle formation. Acta Neuropathol 2002, 103:370-376.

63. Braak H, Braak E: Demonstration of amyloid deposits and neurofibrillary changes in whole brain sections. Brain Pathol 1991, 1:213-216.

64. Delacourte A, Sergeant N, Wattez A, Maurage CA, Lebert F, Pasquier F, David JP: Tau aggregation in the hippocampal formation: an ageing or a pathological process? Exp Gerontol 2002, 37:1291-1296.

65. Brundin P, Melki R, Kopito R: Prion-like transmission of protein aggregates in neurodegenerative diseases. Nat Rev Mol Cell Biol 2010, 11:301-307.

66. Clavaguera F, Bolmont T, Crowther RA, Abramowski D, Frank S, Probst A, Fraser G, Stalder AK, Beibel M, Staufenbiel M, Jucker M, Goedert M, Tolnay M: Transmission and spreading of tauopathy in transgenic mouse brain. Nat Cell Biol 2009, 11:909-913.

67. Frost B, Diamond Ml: Prion-like mechanisms in neurodegenerative diseases. Nat Rev Neurosci 2010, 11:155-159.

68. Gomez-Ramos A, Diaz-Hernandez M, Cuadros R, Hernandez F, Avila J: Extracellular tau is toxic to neuronal cells. FEBS Lett 2006, 580:4842-4850.

69. Frost $B$, Jacks RL, Diamond Ml: Propagation of tau misfolding from the outside to the inside of a cell. J Biol Chem 2009, 284:12845-12852.

70. Diaz-Hernandez M, Gomez-Ramos A, Rubio A, Gomez-Villafuertes R, Naranjo JR, Miras-Portugal MT, Avila J: Tissue-nonspecific alkaline phosphatase promotes the neurotoxicity effect of extracellular tau. $\mathrm{J}$ Biol Chem 2010, 285:32539-32548.

71. Davey GP, Peuchen S, Clark JB: Energy thresholds in brain mitochondria. Potential involvement in neurodegeneration. J Biol Chem 1998, 273:12753-12757.

72. Davey GP, Clark JB: Threshold effects and control of oxidative phosphorylation in nonsynaptic rat brain mitochondria. J Neurochem 1996, 66:1617-1624.

73. Bigio EH, Vono MB, Satumtira S, Adamson J, Sontag E, Hynan LS, White CL, Baker M, Hutton M: Cortical synapse loss in progressive supranuclear palsy. J Neuropathol Exp Neurol 2001, 60:403-410. 
74. Price JL, Ko Al, Wade MJ, Tsou SK, McKeel DW, Morris JC: Neuron number in the entorhinal cortex and CA1 in preclinical Alzheimer disease. Arch Neurol 2001, 58:1395-1402

75. Suzuki M, Desmond TJ, Albin RL, Frey KA: Cholinergic vesicular transporters in progressive supranuclear palsy. Neurology 2002, 58:1013-1018.

76. Thies $\mathrm{E}$, Mandelkow EM: Missorting of tau in neurons causes degeneration of synapses that can be rescued by the kinase MARK2/ Par-1. J Neurosci 2007, 27:2896-2907.

77. Kimura T, Fukuda T, Sahara N, Yamashita S, Murayama M, Mizoroki T, Yoshiike Y, Lee B, Sotiropoulos I, Maeda S, Takashima A: Aggregation of detergent-insoluble tau is involved in neuronal loss but not in synaptic loss. J Biol Chem 2010, 285:38692-38699.

78. Lu DC, Rabizadeh S, Chandra S, Shayya RF, Ellerby LM, Ye X, Salvesen GS, Koo EH, Bredesen DE: A second cytotoxic proteolytic peptide derived from amyloid beta-protein precursor. Nat Med 2000, 6:397-404.

79. Kuida K: Caspase-9. Int J Biochem Cell Biol 2000, 32:121-124.

80. Hashimoto M, Rockenstein E, Crews L, Masliah E: Role of protein aggregation in mitochondrial dysfunction and neurodegeneration in Alzheimer's and Parkinson's diseases. Neuromolecular Med 2003, 4:21-36.

81. Simoneau S, Rezaei H, Sales N, Kaiser-Schulz G, Lefebvre-Roque M, Vidal C, Fournier JG, Comte J, Wopfner F, Grosclaude J, Schätzl H, Lasmézas CI: In vitro and in vivo neurotoxicity of prion protein oligomers. PLoS Pathog 2007, 3:e125.

82. de Calignon A, Fox LM, Pitstick R, Carlson GA, Bacskai BJ, Spires-Jones TL, Hyman BT: Caspase activation precedes and leads to tangles. Nature 464:1201-1204.

83. Margittai M, Langen R: Side chain-dependent stacking modulates tau filament structure. J Biol Chem 2006, 281:37820-37827.

doi:10.1186/1750-1326-6-39

Cite this article as: Lasagna-Reeves et al:: Tau oligomers impair memory and induce synaptic and mitochondrial dysfunction in wild-type mice. Molecular Neurodegeneration 2011 6:39.

\section{Submit your next manuscript to BioMed Central and take full advantage of:}

- Convenient online submission

- Thorough peer review

- No space constraints or color figure charges

- Immediate publication on acceptance

- Inclusion in PubMed, CAS, Scopus and Google Scholar

- Research which is freely available for redistribution

Submit your manuscript at www.biomedcentral.com/submit 